\title{
INFÂNCIA CONTEMPORÂNEA: AS MANIFESTAÇÕES TELEVISIVAS NAS
} CULTURAS LÚDICAS.

\author{
Jéssika Naiara da Silva1 José Milton de Lima ${ }^{2}$ Leonardo de Angelo Orlandi ${ }^{3}$ Susana Angelin Furlan ${ }^{4}$ \\ ${ }^{1}$ Graduanda em Pedagogia pela FCT/UNESP, ${ }^{2}$ Professor Doutor na FCT/UNESP, departamento de Educação, ${ }^{3}$ Mestrando em \\ Educação pela FCT/UNESP, ${ }^{4}$ Graduanda em Educação Física pela FCT/UNESP. E-mail: jessika 4@hotmail.com. PIBIC/CNPq.
}

\section{RESUMO}

O presente trabalho assumiu como objetivo central analisar de que maneira as mídias, em especial a televisão, estavam presentes no cotidiano das crianças de uma instituição de Educação Infantil no município de Álvares Machado-SP. Considerando que os pais/responsáveis e os educadores exercem papel fundamental na mediação da cultura, a investigação buscou levantar posicionamentos que podem ser assumidos frente ao tema, visando uma educação de qualidade. Tal processo visa colaborar na formação de cidadãos mais conscientes, críticos, autônomos. A pesquisa tem como suporte teórico a Teoria HistóricoCultural, Sociologia da Infância e autores da Comunicação Social. A metodologia utilizada é de natureza qualitativa, caracterizando-se como Pesquisa Etnográfica. Os resultados alcançados demonstraram que as crianças pesquisadas têm contato direto com a televisão e que a programação preferida delas são: os desenhos animado, os programas, as novelas e os filmes. Essa relação é manifestada nas culturas lúdicas infantis, nas roupas, calçados, mochilas e objetos.

Palavras-chave: Mediação; Infância; Mídias.

\section{CONTEMPORARY CHILDREN: DEMONSTRATIONS TELEVISION IN CULTURES PLAYFUL.}

\begin{abstract}
This study took as its central objective to analyze how the media, especially television, were present in the daily lives of children in a kindergarten institution in the city of Álvares Machado-SP. Whereas parents / guardians and educators play a key role in mediating culture, research has attempted placements that can be made against the issue to a quality education. This process aims to collaborate in forming citizens more aware, critical, autonomous. The research is supported by the theoretical Historic-Cultural Theory, Sociology of Childhood and author of Social Communication. The methodology is qualitative in nature, characterized as Ethnographic Research. The results showed that the children have direct contact with the television and that programming preferred them are: the cartoon, programs, soap operas and movies. This relationship is manifested in cultures playful children's clothes, shoes, backpacks and objects.
\end{abstract}

Keywords: Mediation; Childhood; Medias. 


\section{INTRODUÇÃO}

O presente trabalho apresenta 0 projeto de pesquisa, "Culturas lúdicas e mediações no contexto escolar", financiado pelo Programa Institucional de Bolsa de Iniciação Científica PIBIC/CNPQ. A pesquisa foi realizada em uma instituição de Educação Infantil no Município de Álvares Machado SP, na qual, participaram aproximadamente 180 crianças na faixa etária entre três e cinco anos e conta com um quadro de nove professoras.

A investigação procurou compreender os significados que as educadoras revelam sobre as culturas lúdicas infantis e, ainda, se os processos de mediação valorizam a brincadeira como forma de conhecimento, de expressão, de comunicação, de desenvolvimento da criança no mundo e com o mundo.

As atividades lúdicas estão diretamente ligadas às experiências e vivências das crianças, assim, é necessário conhecer e considerar a realidade em que elas estão inseridas, ou seja, são representações do meio social, pois as crianças não nascem sabendo brincar, elas aprendem com os irmãos mais velhos, com pais, vizinhos e pares.

Nesse sentido, as crianças trazem para a escola diversos conhecimentos, pois não são tábulas rasas a serem preenchidas pelos professores, pelo contrário, a maioria das crianças traz informações não apenas de sua realidade, mas também informações que foram obtidas através do contato direto com os meios de comunicação.

Dessa forma, faz-se necessário que os educadores busquem identificar os conteúdos oriundos das mídias, em especial da televisão, os quais se revelam nas brincadeiras infantis, nas falas das crianças e nas atitudes; e assim saibam problematizar e mediar tais relações entre crianças e mídias, gerando um desenvolvimento pautado no respeito às culturas da infância $e$ valorizando a atividade lúdica na Educação Infantil como um elemento promotor de humanização.

\section{OBJETIVOS}

- $\quad$ Analisar de que maneira as mídias, em especial a televisão, influenciam as culturas lúdicas das crianças, buscando explicitar alguns tipos de influências exercidas nas brincadeiras e na cultura de pares.

- Compreender os significados que as educadoras têm sobre as culturas lúdicas infantis, e verificar se valorizam a brincadeira como forma de conhecimento, de expressão, de comunicação, de desenvolvimento da criança no mundo e com o mundo.

- Levantar posicionamentos que possam ser assumidos frente ao tema, e assim colaborar no processo de formação continuada de professores, visando instrumentalizá-los para que consigam superar concepções e representações que são entraves para o emprego das atividades lúdicas como recursos pedagógicos na Educação Infantil.

\section{FUNDAMENTAÇÃO TEÓRICA}

Mello (2007, p. 90), apoiada na Teoria Histórico Cultural, destaca a criança como um ser histórico-cultural, que é "desde muito pequena, capaz de explorar os espaços e os objetos que encontra ao seu redor, de estabelecer relações com as pessoas, de elaborar explicações sobre os fatos e fenômenos que vivencia". Através da convivência e das experiências sócio-culturais a criança vai se apropriando dos significados presentes no mundo e se humanizando.

Já a Sociologia da Infância, concebe a criança como um sujeito social com características próprias, que percebe o mundo de maneira diferente do adulto e que, além disso, tem distintas formas de comunicação e interação entre as pessoas e objetos, expressas através do 
brincar. Redin (2009, p. 123) explica que por meio da "[...] brincadeira a criança mergulha na vida, criando um espaço que expressa, que atribui sentido e significado aos acontecimentos". Sarmento (2003, p.15) acrescenta, que diferentemente aos adultos, para as crianças não há distinção entre brincar e fazer coisas sérias, "sendo o brincar muito do que as crianças fazem de mais sério". Porém, a criança não nasce sabendo brincar, pois este tipo de atividade não é inato no ser humano, mas uma atividade repleta de significação social que necessita ser aprendida assim como tantas outras.

Nesse sentido, os ambientes colaboradores do processo de humanização são determinantes na formação da criança. Em geral, as instituições que mais estão presentes na vida da maioria das crianças são: a família, a igreja e a escola. A Educação Infantil constitui-se, então, como importante espaço de socialização, cuidado, local de aprendizagem e desenvolvimento onde a criança se apropria das qualidades tipicamente humanas que são externas a ela (MELLO, 2007).

A criança, em idade pré-escolar, está em processo de formação de conhecimentos, habilidades e qualidades psíquicas mais gerais e fundamentais para a vida em sociedade; dito de outro modo, aquisição qualitativa e quantitativa da linguagem, ação sobre os objetos, percepção, pensamento, memória, imaginação, concentração, orientação espaço-temporal, domínio da vontade, maior socialização, desenvolvimento da motricidade e da personalidade, etc.

Nessa perspectiva, a Teoria HistóricoCultural aponta que a brincadeira (jogos de papéis) é entendida como atividade principal no desenvolvimento da criança na idade pré escolar. Por atividade principal, compreende-se ser aquela que gera maior influência no desenvolvimento da criança em determinada idade. Segundo Leontiev
(1987, apud FACCl, 2006, p.13) "o desenvolvimento dessa atividade condiciona as mudanças mais importantes nos processos psíquicos da criança e nas particularidades psicológicas da sua personalidade".

Brougère $(1998$, p. 6$)$ afirma que a cultura lúdica (conjunto de procedimentos que tornam possível o jogo; referências que permitem identificar tal atividade como jogo) está inserida em uma cultura geral, consequentemente se apodera de elementos como a mídia para compor-se. "A televisão, assim como o brinquedo, transmite hoje conteúdos e às vezes esquemas que contribuem para a modificação da cultura lúdica que vem se tornando internacional". Desde muito cedo, as crianças têm contato com os meios de comunicação e, nessa interação, elas se apropriam dos conteúdos e os expressam por meio das brincadeiras.

A respeito da presença da mídia no contexto escolar, Buckingham (2007, p. 293) afirma: "é extraordinário que o currículo das escolas continue a negligenciar as formas de cultura e comunicação que cominam tão inteiramente o século $X X$ e continuarão a dominar o século XXI". Segundo o autor, duas são as visões que imperam quando relacionamos mídia e crianças; a primeira de cunho mais conservador aponta que as crianças são passivas $e$ vulneráveis, e a segunda compreende que a criança é um ser que nasce com competências para as mídias e que sabe tudo a respeito destas.

Podemos perceber que ambas as visões possuem concepções distintas ao tratarem sobre a relação mídia e criança; assim, é relevante entender quais concepções os professores possuem sobre criança, infância, brincadeiras e mídias, pois assim se compreenderá como acontece a mediação no contexto da Educação Infantil. É impossível negar o contato da criança com as mídias, por isso ressalta-se que o educador deve estar atento as ações que a 
criança apresenta - em especial nas brincadeiras - para que assim possa exercer o seu papel de mediador de forma a ajudá-las a refletir sobre os conteúdos produzidos. "As crianças apenas poderão tornar-se 'cidadãs ativas', capazes de fazer escolhas sensatas em questões políticas, se forem consideradas capazes de fazê-lo" (BUCKINGHAM, 2007, p. 245).

A Teoria Histórico-Cultural, ressalta que o docente se torna o mediador, ou seja, é aquele que tem conhecimentos sobre a criança e a infância e, a partir disso, propõe situações intencionalmente desafiadoras auxiliando 0 desenvolvimento da criança. Vygotsky (1988, apud MELLO, 2007, p.98) indaga que o professor atua na zona de desenvolvimento próximo "que se expressa pelo que a criança não é ainda capaz de fazer de forma independente, mas pode fazer com ajuda do outro". Aquilo que está latente ou em estado de formação pode ser desenvolvido com a intervenção docente, já que na zona de desenvolvimento próximo está alocado o estágio em que há aprendizagem. Portanto, a atuação com pares, adultos (dentre eles, os professores) e objetos são fundamentais para o desenvolvimento multilateral da criança.

Nesse sentido, o educador deve estar presente nos momentos de brincadeiras das crianças, sempre interagindo, conversando e observando a concepção que as crianças têm em relação às brincadeiras com conteúdos das mídias, e assim, atuar problematizando as questões que suscitam durante as atividades.

Nas brincadeiras infantis, o objeto brinquedo assume um espaço privilegiado. Porém, essa importância já é conhecida pelas mídias, em geral, pois são diversos os produtos, brinquedos, objetos, roupas e calçados desenvolvidos para o público infantil, tais produtos estão presentes a todo o momento nas atividades lúdicas, na cultura de pares e nas conversas das crianças, sendo possível observar o contato direto com as mídias, porém é a televisão que se sobressai.

Nessa perspectiva, em relação às brincadeiras e produtos infantis influenciados pelas mídias, Girardello (2010, p.4) aponta que "os heróis, heroínas e aventuras da TV são usados como matéria-prima da vida de fantasia das crianças. As narrativas da televisão funcionam como uma espécie de pré-roteiro para a brincadeira imaginativa das crianças". Perguntamo-nos, então: por que não aproveitar essas narrativas na Educação Infantil e problematizar e enriquecer os conteúdos que alimentam a imaginação das crianças durante as atividades lúdicas?

Para tal posicionamento, é preciso consciência por parte do educador para que esse tipo de linguagem seja incorporado nas práticas cotidianas, ou seja, o papel do professor não é o de impedir as vivências lúdicas das crianças, com argumentos e conteúdos assimilados em outros espaços sociais ou pela televisão, mas, a partir da constatação, ressignificar as experiências assimiladas pelas crianças e auxiliar para a incorporação de outros referenciais na esfera lúdica.

\section{METODOLOGIA}

$\mathrm{Na}$ busca de elucidar os objetivos propostos a investigação adotou a metodologia qualitativa, pois não tem como objetivo enumerar e/ou medir dados coletados, assim focaliza um determinado espaço social e cultural, visando compreender seus valores e práticas (VIÉGAS, 2007, p. 104).

Dessa forma, elegeu a Etnografia como suporte metodológico. Para Lüdke e André (1986, p. 6) esse procedimento "tem um sentido muito próprio: é a descrição de um sistema de significados culturais de um determinado grupo", do qual o ensino deve ser pensado dentro de um contexto cultural amplo. Desse modo, essa 
abordagem metodológica implicou em: estar no local, participar, observar, conversar e registrar as experiências por escrito.

Em relação aos procedimentos metodológicos, a pesquisa utiliza técnicas de observação, entrevistas, questionários, levantamento bibliográfico e diário de campo. Desse modo, a metodologia e os procedimentos adotados foram aplicados no trabalho de campo realizado pela pesquisadora. Tal processo contemplou nove turmas da Educação Infantil no Município de Álvares Machado/SP, entre elas crianças de três, quatro e cinco anos de idade pertencentes ao Infantil I e Infantil II, totalizando aproximadamente 180 crianças e nove educadoras.

Assim, o conhecimento produzido foi elaborado por meio do aprofundamento teórico e do trabalho de campo, trazendo relatos, conhecimentos e informações a respeito da cultura lúdica e da mediação no contexto escolar, e por fim possibilitou apresentar posicionamentos referentes ao tema.

Número do protocolo de cadastramento no Comitê de Ética e Pesquisa: 802009

\section{DISCUSSÃO DOS RESULTADOS}

As observações realizadas, com base nos tipos de mediações exercidas até o momento, nos mostraram que os sentimentos sobre a infância estão sobrepostos, ou seja, algumas educadoras vêem as crianças como adulto em miniatura, que precisam controlar seus movimentos e, outros, alimentam o sentimento de paparicação que se caracteriza pelo cuidado, mimo, proteção (não pode se expor a perigos para não se machucar). Nas entrevistas, a maioria das educadoras afirmou que a infância é um período que a criança precisa brincar e associam esse fato com um ar de saudosismo. Porém, o que predomina no cotidiano escolar são atividades dirigidas tendo como foco a alfabetização na leitura e escrita, ficando explicitada uma antecipação do Ensino Fundamental.

Outro ponto importante, trata-se de como as educadoras percebem as mídias nas brincadeiras das crianças; a entrevista revelou que grande parte delas entendem que as mídias interferem negativamente, ou seja, elas prejudicam a criança, pois estimulam a violência e a agressividade. Porém, entendemos que as crianças possuem e trazem para a escola um repertório próprio de atividades lúdicas e é papel da escola e do professor ampliar e ressignificar a cultura lúdica, inclusive, aquelas influenciadas pelas mídias.

A análise dos questionários, aplicados com os pais/responsáveis das crianças da instituição pesquisada, permitiu inferir que 99\% das crianças possuem aparelho de televisão em casa, sendo que $85,2 \%$ passam de 1 a 4 horas diárias assistindo televisão. Esses dados refletem no consumo infantil, pois as crianças apresentam materiais escolares, roupas, calçados e brinquedos oriundos das programações infantis. Assim, percebeu-se que a programação preferida das crianças são os desenhos animados, em especial Pica-pau, Turma da Mônica, Pato Donald e Bob Esponja. Entretanto, verificou-se que os desenhos animados suscitam a imaginação infantil, porém, são as propagandas e comerciais, que levam as crianças a desejarem os objetos.

\section{CONSIDERAÇÕES FINAIS}

Em virtude desses elementos, podemos afirmar que no contexto escolar há necessidade de compreender a influência da televisão na cultura lúdica. Tal fator pode favorecer o posicionamento do educador no sentido de compreender melhor a brincadeira, recurso de conhecimento e compreensão do mundo real no qual a criança está inserida, e assim, assumir o papel de mediador das culturas da infância. 
Nesse sentido, a investigação se faz importante devido a sua preocupação com a formação continuada das educadoras da instituição pesquisada, além de fornecer aspectos teóricos e práticos.

Por fim, concluímos que, trabalhar a concepção de educadoras que já atuam durante vários anos na Educação Infantil não é uma meta que se alcança em curto prazo, entretanto, é necessário persistir considerando que as crianças são os sujeitos privilegiados com a inserção do lúdico na instituição, resultando assim na ampliação do repertório de brincadeiras e no desenvolvimento integral das crianças.

\section{REFERÊNCIAS}

BROUGÈRE, G. A criança e a cultura lúdica. Revista da Faculdade de Educação, São Paulo, v.24, n.2. jul./dez., 1998.

\section{BUCKINGHAM, D. Crescer na era das mídias} eletrônicas. São Paulo: Loyola, 2007.

FACCI, M. G. D. Os estágios do desenvolvimento psicológico segundo a psicologia sociohistórica. In: ARCE, A.; DUARTE, N. (orgs.). Brincadeira de papéis sociais na educação infantil: As contribuições de Vigotski, Leontiev e Elkonin. São Paulo: Xamã, 2006.

GIRARDELLO, G. A imaginação e as historias da TV. Disponível em: < Ateliê da Aurora: http://www.aurora.ufsc.be/artigos/artigos_imagina ção.htm>. Acesso em: dia? jun. 2010.

LÜDKE, M.; ANDRÉ, M. E. D. A. Pesquisa em Educação: abordagens qualitativas. São Paulo: EPU, 1986.

MELLO, S. A. Infância e humanização: algumas considerações na perspectiva históricocultural. Perspectiva, Florianópolis, v. 25, n. 1, 83-104, jan./jun. 2007.

REDIN, M. M. Crianças e suas culturas singulares. In: MÜLLER, F.; CARVALHO, A. M. A. (orgs.). Teoria e prática na pesquisa com crianças: Diálogos com William Corsaro. São Paulo: Cortez, 2009.

SARMENTO, M. J. As culturas da Infância nas encruzilhadas da 2 o modernidade. 2003. Disponível em:

http://cedic.iec.uminho.pt/textos de trabalho/texto s/encruzilhadas.pdf>. Acesso em: $0 \overline{5}$ maio 2007.
VIÉGAS, L. . S. Reflexões sobre a pesquisa etnográfica em Psicologia e Educação. Diálogos Possíveis, Salvador, n. 09, p.103-123, jan./jun., 2007. 